\title{
Poblamiento, sociedad y economía en el valle del Guadalentín: el Cerro del Castillo de Lorca entre los siglos V a.C.-I d.C.
}

\author{
Settlement, Society and Economy in the Guadalentin Valley: the Site of \\ Cerro del Castillo de Lorca Between the $5^{\text {th }}$ Century $B C$ and the \\ $1^{\text {st }}$ Century $A D$
}

\begin{abstract}
Leticia LóPEz-MONDÉJAR
Investigadora Postdoctoral de la Fundación Séneca - Agencia Regional de Ciencia y Tecnología de Murcia. Institute of Archaeology, University College London (UCL), Reino Unido letlopez@um.es / m.mondejar@ucl.ac.uk
\end{abstract}

Recibido: 13-04-2011

Aceptado: 18-01-2012

\begin{abstract}
RESUMEN
El presente trabajo aborda un análisis diacrónico del Cerro del Castillo de Lorca, uno de los yacimientos ibéricos más importantes pero también más desconocidos del Sureste peninsular. Partiendo de los datos aportados por los múltiples trabajos arqueológicos desarrollados en dicho centro se ofrece por primera vez una visión amplia que, más allá de esa cultura material, aborda los rasgos sociopolíticos y económicos de este centro ibérico así como su papel en el valle del Guadalentín, insertándolo en la dinámica histórica del Sureste peninsular entre los siglos V a.C.-I d.C.
\end{abstract}

Palabras Clave: Época ibérica. Romanización. Poblamiento. Territorio. Lorca. Valle del Guadalentín. Sureste peninsular.

\begin{abstract}
The 'Cerro del Castillo' of Lorca is one of the most important and unknown Iberian sites of the Region of Murcia, in the Iberian Southeast. The aim of this paper is to analyze diachronically this site through the data provided by the archaeological works carried out and, beyond the recovered material culture, to offer a first approach to the socio-political and economic role of this settlement in the landscape of the Guadalentin valley, placing it in the historical dynamics of the Iberian Southeast between the $5^{\text {th }}$ century B.C. and the $1^{\text {st }}$ century A.D.
\end{abstract}

KEY wORDS: Iberian Culture. Romanization. Settlement. Territory. Lorca. Guadalentín Valley. Iberian Southeast.

SUMARIo 1. Introducción. 2. Un emplazamiento privilegiado: estrategias de control y explotación territorial. 3. El oppidum ibérico y el poblamiento en el valle del Guadalentín. 4. Roma en el Sureste: el valle del Guadalentín entre los siglos II a.C.-I d.C. 5. Conclusiones. Referencias bibliográficas. 


\section{Introducción}

Los últimos trabajos de campo desarrollados en Lorca (Murcia) están ofreciendo una interesante información sobre uno de los núcleos ibéricos más destacados, y también más desconocidos, del Sureste peninsular. Hasta ahora, los estudios que han abordado este yacimiento han ofrecido un análisis completo de los hallazgos documentados en el mismo dejando de lado, sin embargo, una visión amplia sobre aspectos relativos a su dinámica sociopolítica y económica. Éste artículo pretende partir de esos hallazgos para abordar el desarrollo de este centro, analizando los criterios que definen su emplazamiento y su papel en el valle del Guadalentín, así como su desarrollo económico y social durante el periodo ibérico y hasta la definitiva integración de estos territorios en la órbita romana.

El Cerro del Castillo se localiza en la comarca murciana del Campo de Lorca, en el sector suroccidental de la Región de Murcia (Fig. 1). Éste último ha constituido tradicionalmente, por sus características históricas, morfoestructurales y climáticas, un área con personalidad propia e independiente con respecto a otras áreas regionales (Roselló 19681969: 47-49). Su topografía, muy accidentada, está marcada por el curso del río Guadalentín, afluente del Segura que riega esta comarca, favoreciendo tradicionalmente el desarrollo no sólo de los secanos sino también de regadíos en determinadas áreas del valle (Alías 1988a y 1988b).

Al mismo tiempo, el valle del Guadalentín y la denominada depresión prelitoral, por la que discurre parte del curso de dicho río, constituyen una vía de comunicación natural entre la costa levantina, el valle del Segura y las tierras andaluzas (Gil 1990: 83-84). Precisamente en un punto clave de esta ruta se localiza el núcleo de Lorca, en el extremo más septentrional de la Sierra del Caño. Su proximidad al Guadalentín y su emplazamiento privilegiado explican el desarrollo del poblamiento en el entorno del Cerro del Castillo desde época prehistórica (Gil 1990: 8) y muestran las ventajas que definen su posición tanto a nivel estratégico como económico.

Quizás uno de los factores que ha contribuido de forma destacada al desconocimiento de este centro ha sido la amplitud cronológica de la ocupación de todo este sector próximo al Guadalentín. En este sentido, la propia localización actual del núcleo urbano de Lorca, que se extiende en las laderas y a los pies del cerro, hace difícil conocer con mayor precisión determinados aspectos del oppidum ibérico, tales como su urbanismo o su extensión concreta en cada periodo. A ello se suma el hecho de que la trama urbana bajomedieval, dispuesta en terrazas a lo largo de la ladera, destruyó buena parte de las ocupaciones más antiguas desarrolladas en esta área del cerro (Gallardo y González 2006), impidiendo conocer estos aspectos en aquellos sectores que han sido excavados.

La escasa información de la que hoy disponemos sobre el interior del poblado la han ofrecido las excavaciones desarrolladas en los sótanos del Colegio de la Purísima y en la Plaza de Juan Moreno (Martínez y Ponce 2002a: 387-388 y 2006: 78). Las estructuras de tipo doméstico halladas aparecen separadas por calles estrechas, y presentan una planta cuadrada o rectangular, con zócalos de mampostería y paredes de adobes, techadas con entramados de cañas y barro. El terreno se niveló para disponer apropiadamente las viviendas. Por lo que respecta a la extensión del poblado ibérico, al menos durante los siglos IV-III a.C., quedaría limitado al este por el cauce del Guadalentín y al oeste por la rambla del Álamo, cuyo trazado se mantiene en la calle actual del mismo nombre (Martínez y Ponce 2002a: 387388).

También se conocen datos relativos a su muralla, que aparece dispuesta en la zona de ladera, donde tanto en periodos anteriores como durante época medieval se localizan las cercas de la ciudad (Martínez y Ponce 2002a: 387-388). La fortificación se adapta de este modo a la topografía del cerro a través de muros con distinta orientación (Martínez y Ponce 2002a: 387-388). Estos, de 2,20 m de anchura, están construidos con un zócalo de grandes bloques pétreos trabados con tierra y con alzado de adobe y sólo aparecen acabados en una de sus caras, quedando la interior sin terminación en la base, adosándose a la pendiente natural de la ladera $(\mathrm{Pu}-$ jante 2003a; Martínez y Ponce 2006: 78). El yacimiento se constituye como uno de los oppida más

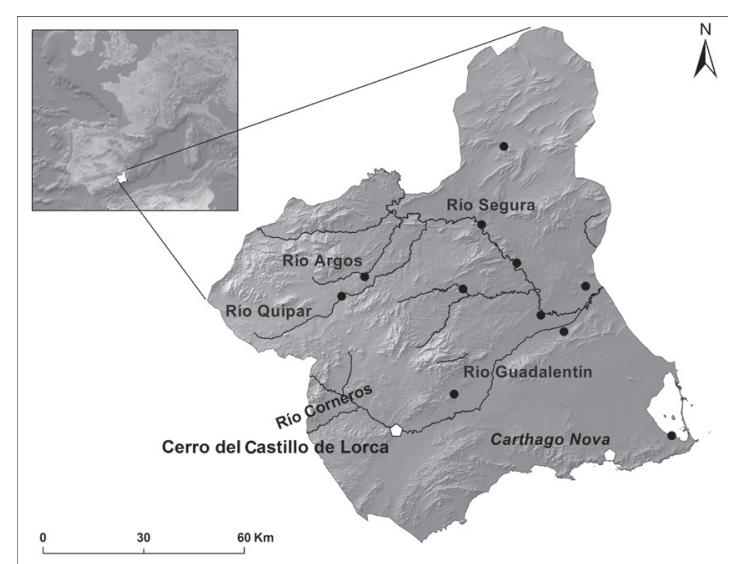

Figura 1.- Localización del Cerro del Castillo entre los principales centros ibéricos del Sureste y en conexión con el núcleo de Carthago Nova. 


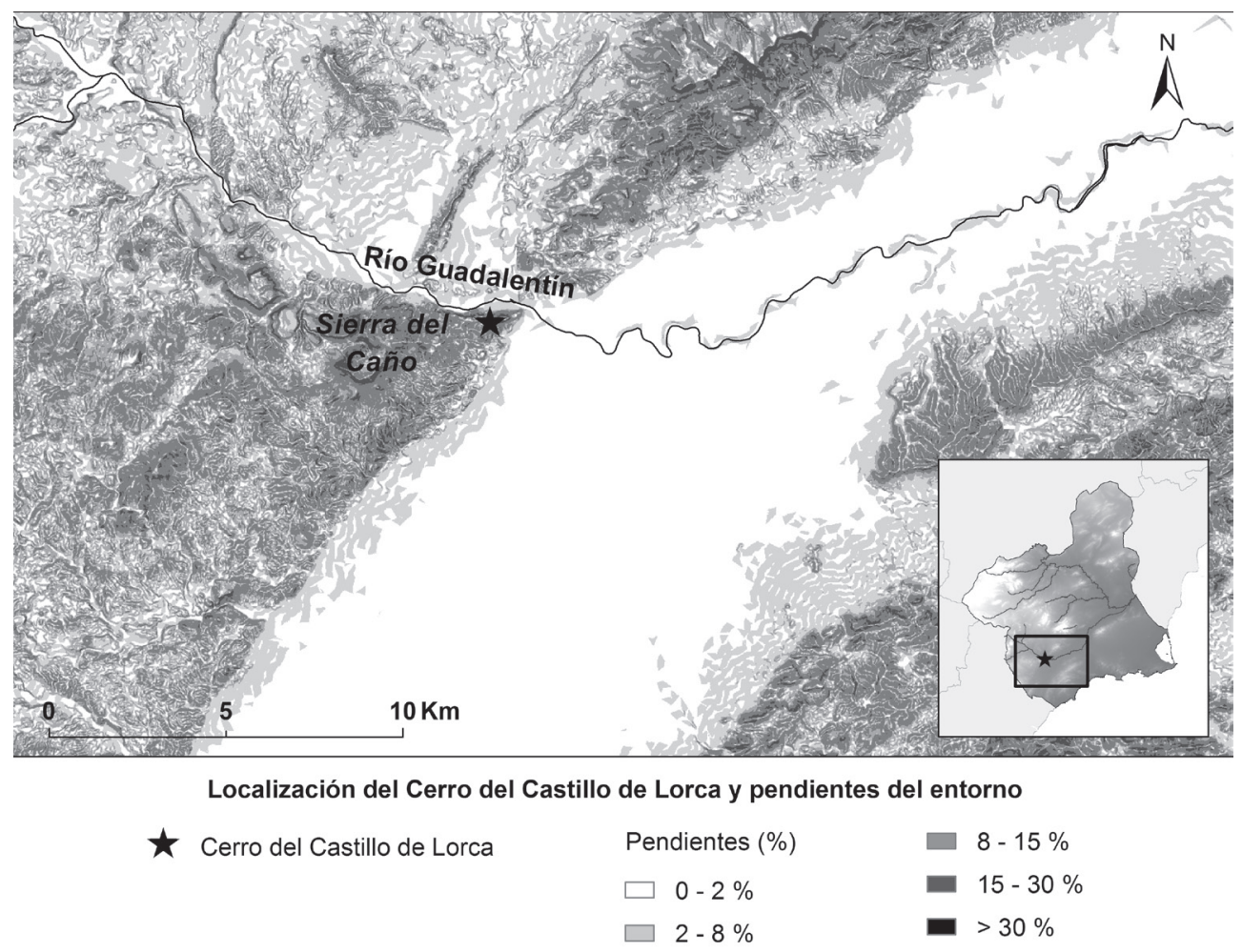

Figura 2.- Localización del yacimiento y pendientes de su entorno.

destacados del área murciana tanto por su amplia cronología como por su posición estratégica, factor este último que será clave en el desarrollo de este asentamiento lorquino y en la continuada ocupación de esta área hasta la actualidad.

\section{Un emplazamiento privilegiado: estrategias de control y explotación territorial}

Precisamente ese carácter estratégico es uno de los rasgos que mejor define el emplazamiento del Cerro del Castillo, localizado en un sector elevado que le permite un amplio control del territorio y de las tierras de su entorno. Dicha posición favorece también sus posibilidades defensivas, completadas con defensas artificiales que además le permiten lograr una posición dominante frente al resto de asentamientos documentados, siendo visible desde todo el valle. Junto a las murallas, las fuertes pendientes del cerro (superiores al 17\%), defienden también el asentamiento protegiéndolo además de las avenidas fluviales que históricamente han afectado al núcleo lorquino y a las tierras más próximas al Guadalentín (Fig. 2).

A todo ello se une la proximidad de este centro al valle de dicho río, vía natural de tránsito que mar- cará en gran medida el desarrollo socioeconómico de dicho núcleo. Su importancia y la participación del Cerro del Castillo en los intercambios que se desarrollarán a lo largo de ella se constatan ya desde época prehistórica. Esta ruta ha tenido además una amplia continuidad histórica, como reflejan los itinerarios de época tardía, las fuentes medievales, los relatos de viajeros de época moderna e incluso el trazado de la actual autovía del Mediterráneo. En época romana con la nueva calzada, la Vía Augusta, la ruta se consolidará definitivamente, funcionando como vía de unión entre los importantes centros mineros de Carthago Nova y Castulo (Belda 1975; Brotóns y Ramallo 1989: 108-15). En época ibérica su papel de enlace con los territorios de la Alta Andalucía representará además un elemento fundamental para el desarrollo de la cultura ibérica en todo el ámbito regional.

Junto a dicho control, cabe también señalar la conexión visual que el Cerro del Castillo establece con otros núcleos del entorno que completarán el control de dicho territorio, como el localizado en el Coto de los Tiemblos o el situado en la Torre de Sancho Manuel. El primero es el único centro ibérico de la comarca que muestra también fortificaciones, mientras que el segundo, de un momento anterior (siglos VII-VI a.C.), y reocupado en época 

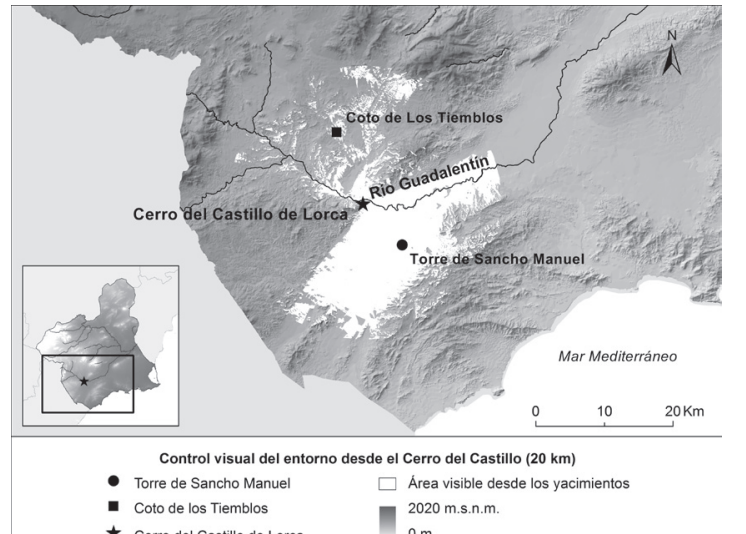

2020 m.s.n.m.

Figura 3.- Control visual desde el Cerro del Castillo y los núcleos localizados en la Torre de Sancho Manuel y el Coto de Los Tiemblos.

ibero-romana, constituirá un punto destacado en el control de la ruta que desde el Guadalentín alcanza las tierras septentrionales almerienses, como refleja más tarde la torre de época medieval aún conservada (Martínez 1996) (Fig. 3).

En definitiva, la propia localización del oppidum, sus fortificaciones, su amplia cuenca visual, su extensión y su cultura material lo diferencian ampliamente de otros establecimientos ibéricos emplazados en el valle, situándolo a la cabeza del poblamiento de toda esta zona. Desde él debió organizarse y articularse el resto del territorio, participando en los intercambios vinculados a dicha ruta, como reflejan los materiales recuperados en su necrópolis y el desarrollo económico y social que éstos denotan.

Junto a ese carácter estratégico, y atendiendo a esas ventajas económicas, un segundo aspecto define el emplazamiento privilegiado de este centro: su localización en un área rica en recursos de todo tipo que constituirán, en gran parte, su base económica así como la de la mayoría de los núcleos ibéricos de la comarca. Como indicábamos, tanto la ocupación histórica de estas tierras como las fuentes documentales nos informan de un área especialmente rica desde el punto de vista agrícola y con amplias posibilidades ganaderas en las sierras del entorno (Gil 1990: 8; López et al. 1986: 232) (Fig. 4).

También la explotación forestal debió constituir un factor importante en la economía de dicho centro, al igual que se observa en otros yacimientos de la comarca, como el emplazado hasta el V a.C. en El Churtal (Fig. 5). En este sentido, los escasos datos paleoambientales disponibles apuntan a una mayor extensión de las áreas forestales en época pre y protohistórica, estando documentada la utilización de maderas así como las actividades de caza y reco-

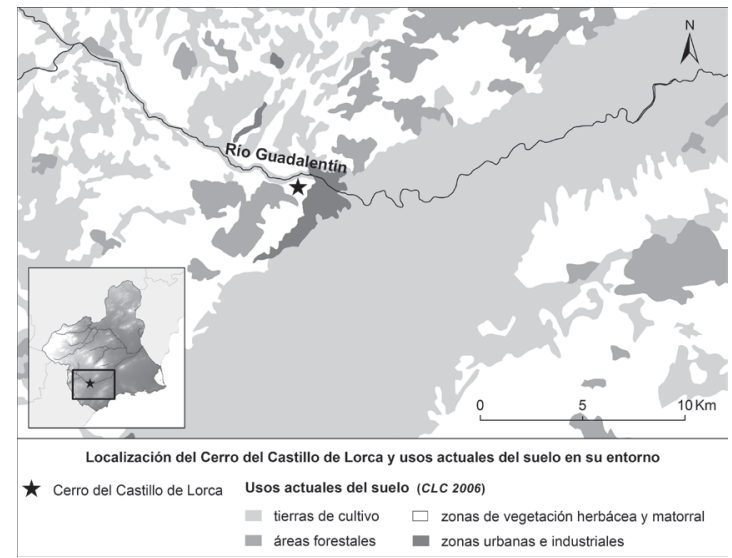

Figura 4.- Localización del yacimiento y usos actuales del suelo en el entorno del mismo (Corine Land Cover 2006).

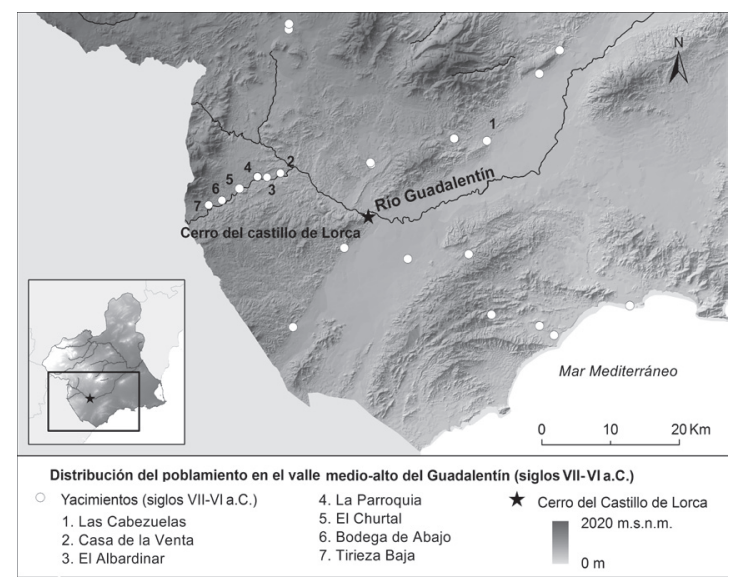

Figura 5.- Distribución del poblamiento durante los siglos VII-VI a.C. y localización de los principales núcleos citados en el texto.

lección en otros asentamientos ibéricos del Sureste y sur peninsular, como en la vecina comarca de Los Vélez (Chávez et al. 2002: 35-46 y 90-5; Iborra 2000: 83-4; Martínez y Muñoz 1999: 37-46; Morgenroth 2004: 111-15; Pérez 1995: 11-12; Prados et al. 1991: 276-77; Santos 1994: 43-47). En el valle del Guadalentín está constatado el uso de madera como combustible en algunos de los hornos cerámicos hallados en el Cerro del Castillo, así como para la cubrición de algunas de las estructuras halladas en el núcleo de la Torre de Sancho Manuel (García et al. 2006: 329-32; Martínez 1996: 151-54; Martínez y Ponce 2002a: 387-88; Ramírez 2004: 177).

Si bien la explotación de los recursos agropecuarios y forestales fue clave en el desarrollo de este centro, son precisamente las actividades de intercambio las que claramente lo diferencian del resto 
de los establecimientos ibéricos de la comarca y las que lo situarán a la cabeza del poblamiento de todo el área. Junto a ellas cabe destacar también las actividades artesanales, y en menor medida, el desarrollo de aquellas relacionadas con la explotación minera y la metalurgia.

Por lo que respecta a las primeras el Cerro del Castillo se constituyó ya desde época ibérica en un importante centro de intercambio gracias a su localización. Reflejo de ello es la riqueza de su necrópolis y su amplia variedad de importaciones. Entre éstas, y para época ibérica, son especialmente destacadas las producciones áticas (García Cano 2004) (Fig. 6). A ellas cabe sumar las importaciones púnicas que alcanzaron también este centro favorecidas ya desde época temprana por su localización en un área intermedia entre el mundo púnico de la costa y el ibérico del interior (Martínez Alcalde 1998: 3032 y 2006; Martínez y Ponce 2002b: 160; Sánchez de Prado 2008: 77). Será sin embargo en los niveles datados en los siglos previos al cambio de Era cuando las producciones foráneas se multipliquen, y no sólo en el cerro sino también a lo largo del valle. En el propio asentamiento se localizan en este momento áreas destinadas a albergar recipientes de transporte y almacenamiento, lo que hace pensar en su funcionamiento como centro de mercado (Martínez y Ponce 2002a: 387-88). En esos sectores de almacenamiento, y junto a las ánforas de saco destina-

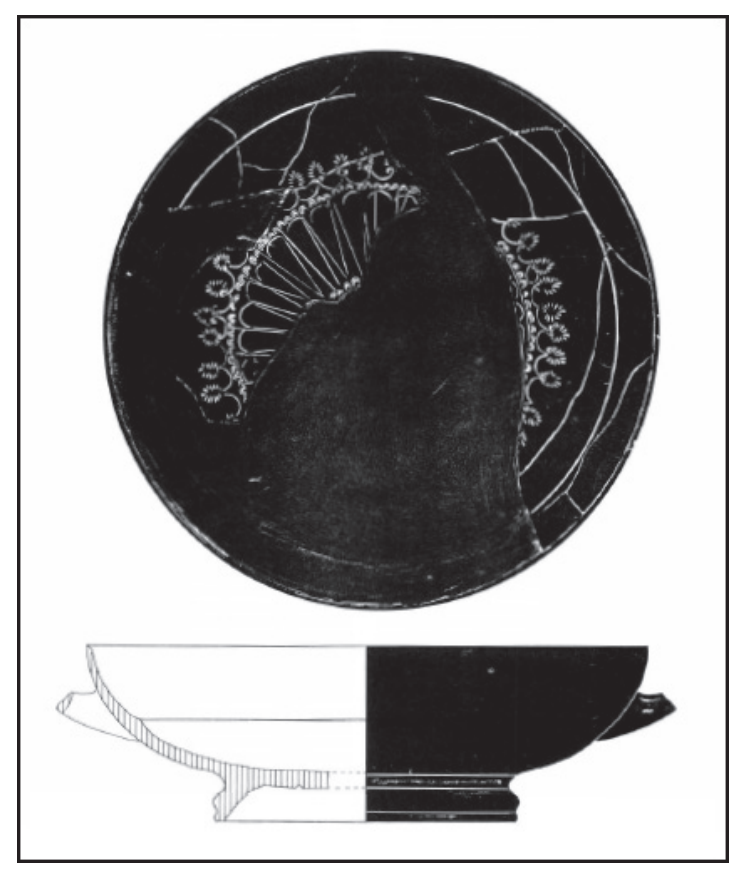

Figura 6.- Kylix ática de clase delicada (García Cano 1989-1990: 96, fig. 1). das a productos locales, encontramos producciones de Campamentos Numantinos, recipientes itálicos para salazones y vinos, y cerámica de mesa Campaniense A (Lamboglia 23, 27, 28, 34, 36 y 68), B y B-oide (Lamb. 1, 2, 3 y 5) (Fig. 7). A ellas se suman además producciones helenísticas e importaciones norteafricanas (García Lorca 2003; Martínez 2008; Ponce 1997 y 1998b; Pujante 2003a; Sánchez 2002: 142; Sánchez 2004: 112-14; Sánchez y Medina 2004).

El Cerro del Castillo se presenta así no sólo como un núcleo redistribuidor de mercancías llegadas de diversos puntos del Mediterráneo, sino también, y especialmente en época ibero-romana, como un centro de almacenamiento de productos. En esta línea se explicaría el gran número de ánforas recuperadas en los trabajos de desfonde realizados en la Alameda de Menchirón, así como en otros sectores del casco urbano lorquino, como la calle Floridablanca, la Plaza de Juan Moreno y La Alberca. En esta última se halló una habitación de tendencia circular donde se conservaba un depósito de abundantes ánforas completas, amortizadas en el 175 a.C. (Martínez 2008; Martínez Alcalde 1998 y 2006).

Todos estos hallazgos confirman la participación activa y continuada de dicho núcleo en los intercambios de la zona desde época ibérica y hasta época romana, con lo que ello supondrá no sólo a nivel económico sino también, como veremos, sociopolítico. Su privilegiada posición en la red de comunicaciones comarcales le permitiría así destinar parte

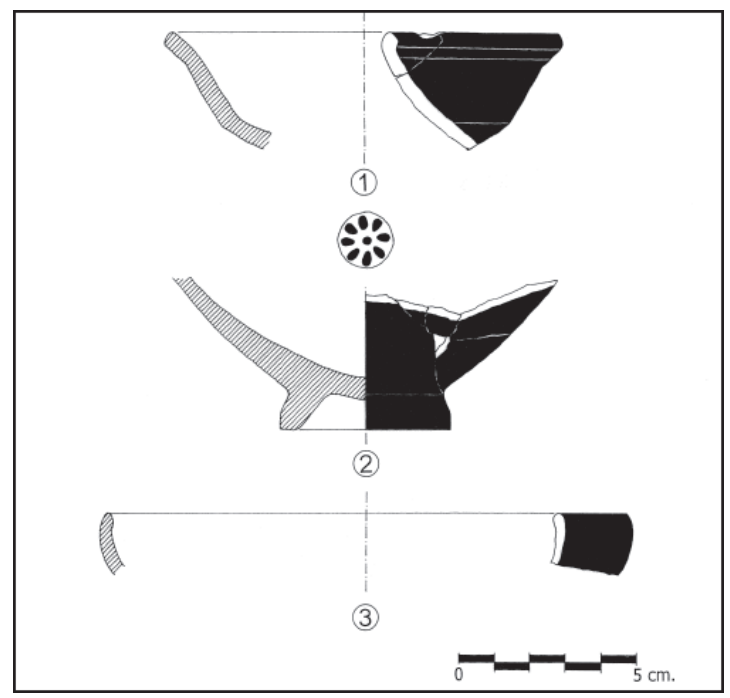

Figura 7.- Cerámicas campanienses A Media procedentes de las excavaciones de la Calle Eugenio Úbeda, n. 12-14. 1. Lamboglia 28, 2. y 3. Lamboglia 27 (Martínez y Ponce 1999b: 327, fig. 27). 
de los excedentes producidos en las ricas tierras de su entorno al intercambio.

En cuanto a las actividades artesanales el hallazgo, a los pies del cerro, de un sector dedicado a ellas muestra también su importancia en época ibérica (Fuentes et al. 2005; Gallardo et al. 2007; Martínez y Ponce 1999a: 228). En este sentido, se han localizado dos hornos en niveles ibéricos en la confluencia de la Avenida Juan Carlos I y la calle Carril de Caldereros, construidos en barro y con una cámara de combustión con espiga central (Pérez 2004: 34$35)$. Junto a ellos, otros sectores urbanos han ofrecido asimismo fragmentos con deficiencias de cocción y restos de adobes, que permiten interpretarlos como posibles sectores de producción alfarera. Ejemplos de ello los encontramos en la confluencia entre Presbítero Emilio Navarro y la Avenida Juan Carlos I, así como en la calle Eugenio Úbeda 14 (Martínez y Ponce 1999a: 228).

Estas actividades alfareras aparecen ya constatadas desde el siglo VI a.C., como refleja el horno de tradición oriental del sector de la Alberca, y han tenido tradicionalmente un peso importante en el ámbito lorquino y en otros puntos del valle del Guadalentín, especialmente por la presencia de arcillas de especial interés para la alfarería (Esteve et al. 2003: 347-53; Gallardo et al. 2007; Martínez Alcalde 2006). También en conexión con su desarrollo podría interpretarse el carro ibérico hallado en la necrópolis.

Finalmente, y por lo que respecta a las actividades metalúrgicas y mineras, resulta más complicado confirmar su desarrollo para época ibérica. En el caso de las primeras el hallazgo de restos de escorias de fundición en niveles de relleno junto a materiales de época ibérica y su presencia en yacimientos andaluces muy próximos como Bugéjar, Los Valencianos y Macián, interpretadas en esta línea, nos llevan a no descartarlas en el caso lorquino (Martínez Alcalde 2006; Pérez 1995: 11-12). Es ya en los siglos II-I a.C. cuando tenemos constancia de las mismas en Lorca, momento en el que se datan las grandes dependencias localizadas en la calle $\mathrm{Ca}$ rril de Caldereros, puestas en relación directa con la copelación de la plata (Martínez 2008; Martínez y Ponce 1999a: 230-34).

Tampoco contamos por ahora para época ibérica y romana con datos sobre el desarrollo de actividades de explotación minera y de cantería en el entorno del Cerro del Castillo y, en general, en el área comarcal. En cualquier caso, la localización de determinados asentamientos en sectores no especialmente aptos para la explotación agropecuaria y en las proximidades de áreas que ofrecen un interés minero o próximas a canteras, merece un análisis en profundidad, especialmente si pensamos que di- chas actividades sí han sido documentadas en otros centros ibéricos del Sureste y sur peninsular como complemento a una economía de tipo esencialmente agropecuario.

\section{El oppidum ibérico y el poblamiento en el valle del Guadalentín}

\subsection{El tránsito al siglo $\mathrm{V}$ a.C. en la comarca lorquina}

El tránsito al siglo $\mathrm{V}$ a.C. representa un primer momento clave en el desarrollo del mundo ibérico del valle del Guadalentín, implicando importantes cambios en el poblamiento comarcal. Precisamente por ello, y a modo de marco en el que encuadrar no sólo dichas transformaciones sino todo el posterior desarrollo del poblamiento en el área comarcal, resulta fundamental atender brevemente al panorama que encontramos a comienzos de esta centuria en estos territorios.

A lo largo de los siglos VII-VI a.C. y hasta el tránsito al $\mathrm{V}$ a.C. se observa un destacado poblamiento concentrado fundamentalmente en el valle del Corneros, afluente del Guadalentín (Fig. 5). En sus márgenes encontramos emplazados yacimientos como Bodega de Abajo I, El Albardinar I, El Churtal, Casa de la Venta I y Tirieza Baja que se desarrollarán hasta el tránsito al siglo $\mathrm{V}$ a.C.

Se advierten ya en estos momentos previos a dicha centuria claras influencias orientales en todo el Guadalentín, en el que yacimientos como el Castellar de Librilla o Las Cabezuelas de Totana reflejan el papel del valle como eje de comunicaciones entre púnicos e indígenas (Martínez Alcalde 1998; Martínez y Muñoz 1999: 64-5; Ros 1989). Por lo que respecta al Cerro del Castillo, el horno de tradición oriental hallado en La Alberca y fechado en el VI a.C. se interpreta precisamente en conexión con la utilización de esta zona como un área de actividades industriales y mercantiles, en relación con esos intercambios con el mundo fenicio del litoral (Martínez Alcalde 2006; Martínez y Ponce 1999a: 228 y 2002a). Ejemplo de ellos es asimismo el amuleto púnico del $\mathrm{V}$ a.C. localizado en este mismo sector (Sánchez de Prado 2008: 77).

Este paisaje de los siglos VII-VI a.C. se transforma en el tránsito al V a.C., momento en el que se advierte un cambio en la dinámica evolutiva de este sector del Sureste peninsular. El análisis del poblamiento muestra cómo esos establecimientos ocupados en las dos centurias previas se abandonan, y el Corneros se convierte en un área marcada por un amplio vacío poblacional a partir de esta fecha y hasta el I a.C. 
Este panorama coincide además con el que se ha descrito también para las vecinas tierras septentrionales granadinas (Adroher y López 2004), y probablemente está en conexión con las nuevas rutas que, a partir del V a.C., marcarán los intercambios con el mundo griego en toda esta zona peninsular. La ausencia de importaciones áticas en los centros que vemos ocupados en los siglos V-IV a.C., como el localizado en La Parroquia, así como en otros asentamientos del valle medio y alto del Guadalentín, confirman que la zona del Corneros debió quedar fuera de los ejes a través de los que se distribuirán dichas producciones. Así, el hallazgo del conocido centauro de Los Royos en las vecinas tierras de Caravaca, en el interior regional, y los materiales áticos que se documentan en yacimientos como La Chopera (entre ellos un fragmento de figuras rojas datado en la primera mitad del IV a.C.), son sólo un reflejo de la importancia que a partir de estos momentos adquirirá el eje de comunicaciones que representa el valle del Quípar (Brotóns y López 2009). Frente a este sector interior, el Cerro del Castillo, y en general todo el valle medio del Guadalentín, quedará como una zona más próxima al mundo púnico, orientada a las relaciones de intercambio que pudieron establecerse con el mismo. Son precisamente algunos rasgos de esta área los que nos permiten observar esa diferencia con respecto a otros valles regionales a partir del siglo V y hasta el III a.C.

Por un lado, la escasez de poblamiento que define todo este sector y que contrasta con la densidad que muestran otros valles del Sureste en este mismo periodo. Este hecho pudo estar en conexión con ese carácter de zona intermedia entre mundo ibérico y mundo púnico, tal y como ya indicó Lillo (1990). En segundo lugar, también los hallazgos y materiales recuperados, sobre todo en el Cerro del Castillo, son un reflejo de esas relaciones con el mundo fenicio del litoral (Martínez Alcalde 2006; Martínez y Ponce 1999a: 228 y 2002a; Sánchez de Prado 2008). Entre ellos destaca el área documentada en el actual casco urbano lorquino e interpretada como posible sector de culto que, sin embargo, dista mucho del resto de santuarios localizados en el Sureste ibérico. En ella, aún en proceso de estudio, se ha constatado la presencia de un altar cuyos paralelos remiten a modelos orientales. Este hecho no sólo confirma, tal y como indican sus excavadores, esas relaciones con el mundo púnico y sus influjos en el yacimiento, sino además la importancia de este núcleo como centro de intercambio (Cárceles et al. 2011).

En conexión con esta última cuestión, no debemos olvidar que es precisamente también a partir de inicios del V a.C. cuando el núcleo almeriense de Villaricos mostrará un mayor florecimiento, consolidándose a lo largo de esta centuria y de la si- guiente el proceso de expansión fenicia por el valle del Almanzora (Cámalich y Martín 1999: 158-59). A ello debemos sumar la reorientación económica que caracteriza a los núcleos púnicos del litoral desde comienzos del siglo V a.C. y que afectará no sólo a los centros que se hallan bajo la influencia de Villaricos, sino también a los propios asentamientos ibéricos de esta área peninsular. Éstos últimos conocen a partir de ahora un importante desarrollo económico, hasta el punto de que se ha planteado que muchos de ellos estarían produciendo la mayor parte del vino, aceite y cereales que los comerciantes púnicos del Sureste están consumiendo y distribuyendo hacia los mercados exteriores (Delgado et al. 2000: 1781-7).

A pesar de todo lo indicado, el Cerro del Castillo de Lorca, como núcleo principal de todo este sector, y si bien no inmerso directamente en las rutas principales de intercambio con el mundo griego, tampoco quedará totalmente al margen de ellas. Así, durante esta centuria y hasta mediados del IV a.C. se observa la llegada a dicho centro de producciones áticas que, sin embargo, no veremos en el resto de los asentamientos lorquinos de este periodo (Fig. $6)$.

\subsection{Poblamiento y sociedad entre los siglos V-III a.C.}

Tras la desaparición a inicios del V a.C. de muchos de esos establecimientos instalados en la comarca, el Cerro del Castillo es el único, junto al localizado en La Parroquia, que continuará a lo largo de esta centuria. Su carácter de centro principal se pone además de manifiesto en un contexto poblacional

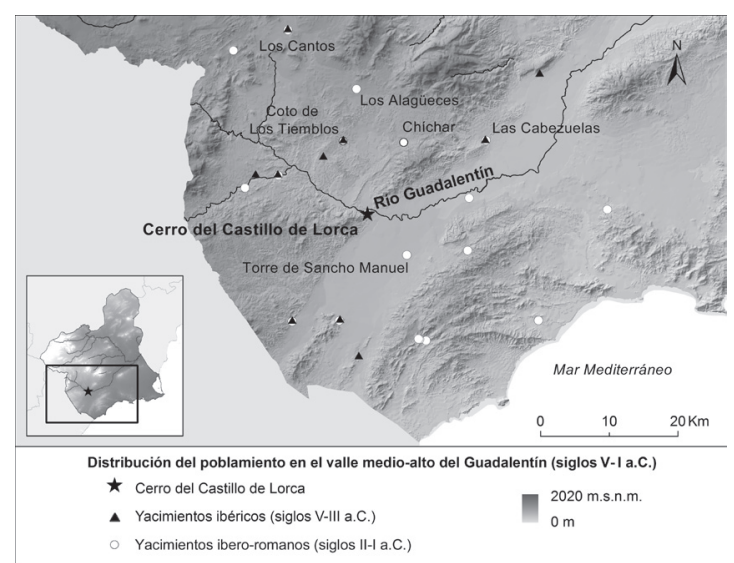

Figura 8.- Distribución del poblamiento ibérico e ibero-romano en el valle del Guadalentín (siglos V-I a.C.). 
definido por asentamientos de mucha menor entidad, situándose a la cabeza de todos ellos (Fig. 8). Entre éstos, cuyo patrón de asentamiento refleja en la mayor parte de los casos un carácter fundamentalmente agropecuario, sólo algunos como el Coto de Los Tiemblos o el emplazado en Los Cantos (Coy) alcanzaron un mayor desarrollo. Al menos en esta línea apunta la muralla documentada en el primero, y los restos escultóricos asociados a la necrópolis de La Fuentecica del Tío Garrulo emplazada en las proximidades del segundo, así como el posible santuario que pudo también estar en conexión con este último. Ambos centros se localizan además junto a vías naturales de comunicación que conectan el valle del Guadalentín y el Cerro del Castillo con el señalado eje del Quípar y con el Noroeste regional.

Frente a estos dos, el resto de los establecimientos ibéricos comarcales presenta una escasa extensión y un registro material definido esencialmente por cerámica común y recipientes de almacenamiento. Quizás el rasgo que mejor define el patrón de asentamiento durante los siglos V-III a.C. es la búsqueda de posiciones que ofrecen un fácil acceso a aquellos sectores más aptos para la explotación agropecuaria. Como indicábamos, únicamente el centro localizado en el Coto de los Tiemblos refleja un interés defensivo y ofrece, junto a Los Cantos, restos de importaciones itálicas. Por el contrario, éstas últimas no han sido halladas en el resto de los asentamientos, hecho que no permite llevarlos más allá del siglo III a.C. y de los primeros momentos de la presencia romana en estos territorios.

Indicativo resulta también que ningún centro aparezca emplazado en las inmediaciones del Cerro del Castillo a lo largo de los siglos V-III a.C. hasta bien entrado el II a.C. Se trata de un rasgo que se repite también en otros importantes núcleos ibéricos regionales y que refleja el control y la explotación directa de esos territorios por parte de dichos oppida. Concretamente, en el caso del núcleo lorquino, los hallazgos recuperados en la ladera y a los pies del sector más oriental de la Sierra del Caño, en la margen derecha del Guadalentín, muestran sin embargo una expansión del área ocupada desde el cerro a esta zona. En ella se observa a lo largo de todo el periodo ibérico una

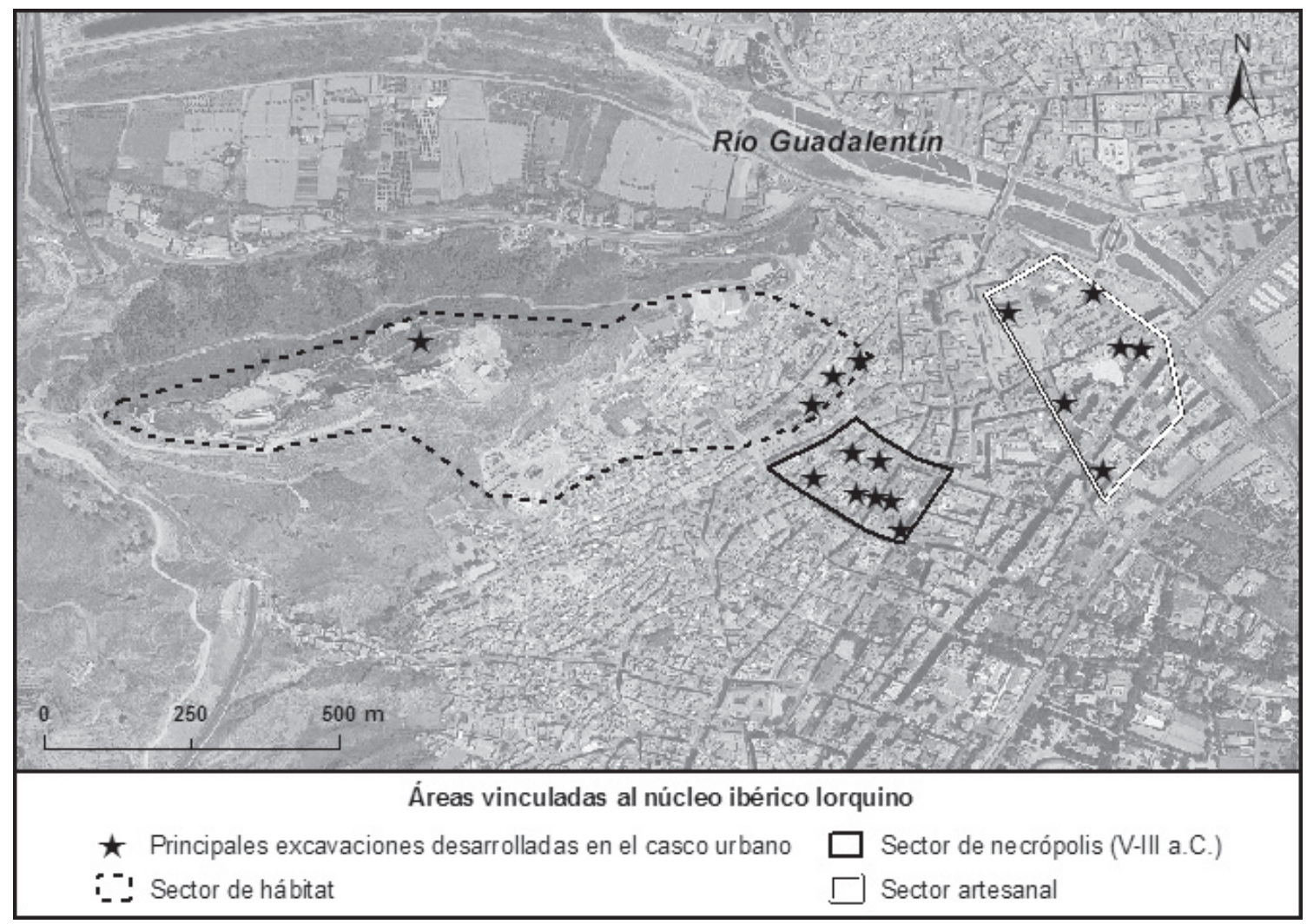

Figura 9.- Localización, en el actual casco urbano de Lorca, de los distintos sectores documentados en el núcleo ibérico del Cerro del Castillo. 
ocupación dispersa vinculada a actividades de tipo agropecuario y artesanal, como reflejan los hornos ibéricos y la balsa de decantación del siglo IV a.C. documentados en las proximidades del Carril de Caldereros (Gallardo et al. 2007; Martínez y Ponce 1999a).

De este modo, y especialmente frente a esos centros secundarios, el Cerro del Castillo se presenta a lo largo de los siglos V-III a.C. como el núcleo principal de un paisaje jerarquizado, marcado por la presencia de un grupo social que ejercería el control de las tierras y los intercambios desde el oppidum. Su posición estratégica no sólo favoreció su desarrollo económico, sino que también implicó una mayor complejidad social, especialmente reflejada en el sector de necrópolis extendido a sus pies y cuya cronología abarca desde el V a.C. hasta época romana (Ramírez 2004: 113-17) (Fig. 9).

Inicialmente localizada entre la calle Álamo y la calle Lope Gisbert, bajo el actual casco urbano lorquino, el área de necrópolis se ampliará en un segundo momento hacia el este de la rambla del Álamo, superponiéndose muchos de sus enterramientos (García Lorca 2003; Martínez 2008) (Fig. 10). Se trata desafortunadamente de una excepción en el marco comarcal ya que al margen de ella, los datos relativos a sectores funerarios son casi inexistentes. Actualmente, únicamente disponemos de aquellos que ha arrojado la necrópolis vinculada al núcleo de Los Cantos, en el sector de Coy, y que, sin embargo, no muestran una entidad similar a la del oppidum. Este panorama se puede hacer extensivo al resto del área regional, siendo únicamente las necrópolis de los principales oppi$d a$ regionales las que aportan un registro similar.

En este sentido, y en conexión con esos aspectos sociopolíticos, los materiales cerámicos recuperados en la necrópolis lorquina constituyen uno de los elementos fundamentales de análisis. Éstos, y entre ellos muy especialmente las importaciones áticas, confirman el papel del Cerro del Castillo como punto clave en los intercambios con el valle del Segura y el mundo levantino. Al mismo tiempo ponen de manifiesto su riqueza y la presencia de un grupo social capaz de participar de esos circuitos de intercambio adquiriendo este tipo de elementos de prestigio al que la mayor parte de la comunidad no tiene acceso en estos momentos. El oppidum controló así un amplio territorio que se extendería más allá de las tierras de su entorno, a juzgar por los rasgos que caracterizan el poblamiento ibérico del valle. Como ejemplo, entre los numerosos materiales publicados tras las labores arqueológicas desarrolladas en el casco urbano lorquino, basta indicar la kylix ática de 'clase delicada' hallada en

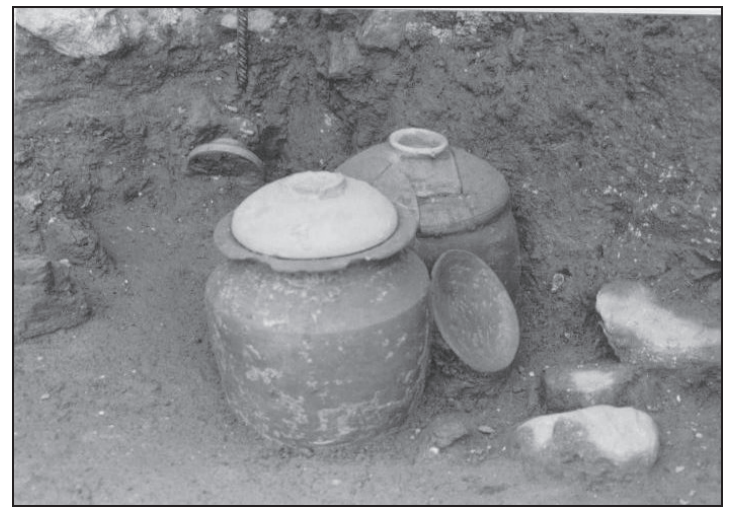

Figura 10.- Urnas ibéricas in situ durante las excavaciones realizadas en la calle Álamo (UE. 1106) (García Lorca 2003: 24, fig. 11).

dicho oppidum, pieza que muestra el importante nivel de riqueza del asentamiento y de su poseedor ya a finales del siglo V a.C. (García Cano 2004).

Junto a esos materiales, un elemento especialmente significativo es el carro ibérico localizado en los solares de la calle Corredera 46 y 47, y datado en el IV a.C. en base a los materiales áticos asociados a él (García et al. 2006; Ramírez 2004:1 77). Cronológicamente coincide así con los restos de carros aparecidos en otras necrópolis del Sureste y la Alta Andalucía (Toya, Baza, Galera), cuyas cronologías se extienden entre el 450/425-350/300 a.C. (Chapa et al. 1999: 82; Fernández y Olmos 1986: 162-65).

De modo general el hallazgo de este elemento conlleva una serie de implicaciones a nivel social y cultural que en el caso de los centros ibéricos pone en evidencia la presencia de un grupo dirigente destacado (García et al. 2006; Fernández y Olmos 1986). Tradicionalmente, aunque existen excepciones, se ha vinculado su aparición con sepulturas pertenecientes a personajes de elevado estatus social dentro de la comunidad, utilizándose de este modo en el mundo ibérico como elemento diferenciador entre los grupos sociales que conviven en un determinado asentamiento o territorio. A través de él dichos grupos pretenden mostrar su posición en la comunidad en su ritual de la muerte, dejando claro el rango social del difunto. Su aparición, sin embargo, no se limita al ámbito peninsular, sino que se repite en otros ámbitos del Mediterráneo prerromano, donde su significado va incluso más allá del mero prestigio social (Fernández y Olmos 1986; Ruiz y Molinos 1993: 218-20).

Como indica R. Olmos (1986), el carro debió ser un motivo muy querido por la aristocracia ibérica, localizándose en sepulturas vinculadas a personajes destacados dentro de la comunidad. Su aparición en determinados centros ibéricos viene así vinculada a 
enterramientos con ajuares destacados y refleja la existencia de una élite indígena, de un artesanado especializado con un alto grado de desarrollo tecnológico y de la inserción de dicho asentamiento en los ejes de comunicación por los que circulan esas influencias mediterráneas de las que se hará eco esa sociedad indígena (Fernández y Olmos 1986).

Precisamente en conexión con esa elite indígena cabe atender a otro rasgo de la necrópolis del Cerro del Castillo: la variedad de tipologías de enterramiento documentadas y de los ajuares asociados a ellas. En general, las sepulturas más numerosas son aquellas definidas por simples enterramientos en urnas y fosas, tumbas en cistas de forma globular, así como otras cubiertas por ladrillos de adobe, estas dos últimas con claros paralelos en Andalucía oriental (Almagro 1982; Blánquez 1994: 212; García Cano 2004; García Lorca 2003; Chapa et al. 1999; Presedo 1982; Ramírez 2004; Ramos y García 2004; Rodríguez 1999). Todas ellas son tipologías que también observamos en aquellas áreas funerarias asociadas a otros yacimientos del Sureste.

Son sin embargo especialmente interesantes aquellas sepulturas que pueden definirse como pertenecientes a personajes destacados dentro de la comunidad: el enterramiento principesco construido con gradas de adobe y localizado en la esquina de las calles Lope Gisbert y Álamo, y el túmulo cuadrangular de la calle Rincón de Moncada. Ambos, datados en los momentos finales del siglo V a.C., se diferencian claramente del resto de los enterramientos de este periodo (Martínez 2008; Ramos y García 2004: 110; Ramírez 2004). Las dos sepulturas vienen además a coincidir cronológicamente (V-IV a.C.) con el momento en el cual se observan en el sur y sureste peninsular nuevas tipologías de tumbas de tipo aristocrático, como el túmulo principesco o la gran cista, de las que tenemos ejemplos en las vecinas necrópolis de El Cigarralejo, Baza y Galera (Presedo 1982: 360; Ruiz y Molinos 1993: 215-16).

Junto a ellos, y diferenciado de aquellas sepulturas con ajuares más pobres o reducidas exclusivamente al enterramiento, aparece un tercer conjunto de tumbas que muestra también una cierta riqueza, aunque sin alcanzar la ofrecida por esas sepulturas principescas. Dichos enterramientos presentan en sus ajuares armas y productos de importación, especialmente cerámicas áticas, que denotan la presencia de un grupo social que debió adquirir cierto estatus dentro de la comunidad, bien a través de la posesión de tierras, del desarrollo de determinadas actividades o por su vinculación con la elite dirigente.

Junto a esa diversidad cabe señalar un aspecto especialmente interesante para este periodo inicial de utilización de la necrópolis: la disposición orde- nada de los enterramientos más modestos en torno a esas tumbas de primer orden (Cárceles et al. 2008; Martínez 2008; Ramos y García 2004). Si atendemos a los paralelos documentados en otros ámbitos ibéricos, esa articulación espacial de la necrópolis no es sino un reflejo más de la estructura social de la comunidad establecida en el Cerro del Castillo, mostrando un vínculo familiar o clientelar entre los individuos enterrados en esas sepulturas secundarias y los personajes a los que pertenecerían aquellas que se han definido como principescas (Almagro 1982: 728-33; Ruiz 1998: 291-93).

Este panorama que observamos desde el V a.C. experimentará una transformación a mediados de la centuria siguiente que debemos poner en conexión con múltiples factores. Entre ellos, son dos los que aparentemente afectan más directamente al valle del Guadalentín y en definitiva al Cerro del Casti1lo: la consolidación de la ruta del Quípar a través del interior regional, y la firma del tratado del 348 a.C., a través del cual los centros púnicos del Sureste obtendrán la exclusiva en el control de la ruta del río Almanzora.

Así, a partir de mediados del IV a.C. se observa un claro descenso en el número de importaciones áticas en el yacimiento y su necrópolis. Si bien se trata de un fenómeno común a otros ámbitos del Mediterráneo en estos momentos, llama la atención que no afecte en cambio a los núcleos emplazados en el interior regional. Muchos de ellos, surgidos a partir de estos momentos, ofrecen materiales áticos a pesar de que no son centros de gran entidad.

Junto al descenso en el número de importaciones áticas, cabe indicar otro cambio destacado en la necrópolis del Cerro del Castillo: a partir de la segunda mitad del IV y durante el III a.C. no se documenta ninguna otra tumba de carácter principesco. Al mismo tiempo se observa una ruptura de la organización espacial previa con la presencia de reiteradas acumulaciones de muchos de los nuevos enterramientos sobre aquellos más antiguos. Se rompe así cualquier vinculación familiar o clientelar entre ellas (Ramírez 2004: 117-18) y, si bien continuamos apreciando una variedad tipológica de enterramientos, la sociedad parece mostrar una jerarquía mucho menos marcada que durante el periodo anterior, buscando quizás nuevos medios para manifestar esas diferencias.

Nos hallamos, por tanto, a lo largo de los siglos V-IV a.C. en el Cerro del Castillo, ante una sociedad compleja y jerarquizada, a cuya cabeza se situaría una elite indígena representada en los citados enterramientos y poseedora de elementos de prestigio social como ese carro ibérico. Junto a ella se define un grupo social intermedio, probablemente vinculado a dicha élite y que pudo tener un carácter guerre- 
ro, especialmente si atendemos tanto a las ricas importaciones áticas como al armamento que muchas tumbas ofrecen (Martínez y Ponce 1999a: 228-229; Ponce 1997: 328-356). Finalmente, quedaría un amplio grupo de población dedicado exclusivamente a la explotación de las tierras del entorno, siendo probablemente con el que se vinculan las sepulturas más pobres. Quizás sea precisamente éste el que ocuparía y explotaría, desde el siglo V a.C. y a lo largo de las dos centurias siguientes, esas tierras bajas situadas en la margen derecha del Guadalentín. El panorama es por tanto muy similar al que se ha definido para otras necrópolis ibéricas del Sureste y el Levante peninsular, como las de El Cigarralejo, La Albufereta o Santa Ana (Almagro 1982: 730).

Estos cambios de mediados del IV a.C. coinciden con la dinámica general del Sureste y con los que se observan en los distintos valles regionales, incluido el del Quípar (Brotóns y López 2009). Desaparecerán en estos momentos muchos de los elementos que denotaban esa fuerte jerarquización social, como los enterramientos aristocráticos, se ampliarán las posibilidades de acceso a los bienes de prestigio y la elite ibérica optará por nuevas formas de representación social más allá de las necrópolis. Aun así, esa élite indígena continuará a la cabeza de la sociedad hasta la llegada de Roma, momento en el que jugará un papel fundamental en muchos de estos centros del Sureste. Al mismo tiempo, será durante la segunda mitad de esta centuria y a lo largo del siglo III a.C. cuando se consolidará el proceso de expansión púnica, con la fundación de nuevos centros y el control de nuevos sectores, incluido el pasillo de Guazamara-Pulpí, vía de comunicación esencial con las tierras lorquinas que aparecerá ya ocupada por nuevos asentamientos (Cámalich y Martín 1999: 158-59). En este marco cabe destacar asimismo la fundación de Carthago Nova, que representará también un elemento clave en el desarrollo de los intercambios en todo este sector del Sureste. Concretamente, será en el siglo III a.C. cuando se observe la llegada de un mayor número de materiales púnicos al núcleo lorquino (Martínez Alcalde 1998; Martínez y Ponce 1999a: 229). Su situación, a medio camino entre el mundo ibérico del interior y el mundo púnico que se desarrolla ampliamente en el litoral, convirtió a toda esta zona en un sector con un carácter particular frente a otras áreas ibéricas del Sureste.

La fundación de Carthago Nova no parece tener consecuencias en el poblamiento comarcal, observándose la continuidad del Cerro del Castillo y de los establecimientos ibéricos situados en el interior lorquino. De este modo, el panorama descrito desde mediados del IV a.C. se mantiene hasta el tránsito de los siglos III-II a.C., momento en el que nue- vas transformaciones afectan a estos territorios, a los núcleos ibéricos del valle y al propio Cerro del Castillo.

\section{Roma en el Sureste: el valle del Guadalentín entre los siglos II a.C.-I d.C.}

\subsection{Transformación y continuidad (siglos II-I a.C).}

La toma romana de Carthago Nova supondrá un punto de inflexión en el desarrollo del mundo ibérico del sur y el sureste peninsular. Si bien la presencia de ánforas púnicas en el Cerro del Castillo de Lorca durante la segunda mitad del siglo II a.C. confirma que el comercio con el mundo púnico del litoral no se interrumpió bruscamente tras la Segunda Guerra Púnica (Martínez 2008), lo cierto es que la presencia de Roma en las costas murcianas representó un cambio en la dinámica política y económica de estos territorios que quedará además reflejado en el propio poblamiento del valle.

Ya desde los primeros momentos del siglo II a.C., e incluso desde finales del III a.C., los hallazgos en el Cerro del Castillo de Lorca y en su entorno más inmediato presentan este sector como una de las áreas donde primero se dejaron sentir los influjos procedentes de Carthago Nova (Martínez y Ponce 2004: 293-96; García Cano 2004; Sánchez y Medina 2004: 327-29).

A lo largo de los siglos II-I a.C. el sector más elevado del cerro continúa ocupado y no será hasta época altoimperial cuando parece abandonarse definitivamente el hábitat en altura, como reflejan también otros yacimientos comarcales. Los datos apuntan así a una clara continuidad del asentamiento $\mathrm{y}$ una convivencia entre tradiciones indígenas $\mathrm{e}$ influencias romanas (Martínez y Ponce 1999a: 22931; Ramallo 1990). Éstas últimas debieron extenderse de forma rápida por el valle del Guadalentín, sin provocar una ruptura brusca con respecto al periodo anterior, como refleja también, en el caso del Cerro del Castillo, el uso continuado de la necrópolis hasta época imperial y la perduración del ritual incinerador en urnas de tradición ibérica (García Lorca 2003: 13-16 y 34-35; Martínez 2008; Ramírez 2004: 113-17).

Frente a ese poblamiento en altura y al margen del sector funerario, se observa también una expansión cada vez más amplia del área ocupada por las laderas y la zona baja del cerro. Se trata de un rasgo que define también a otros centros ibéricos regionales, del levante y del área granadina, como el vecino oppidum de Las Cabezuelas, en Totana (Martínez 2008; Poveda 1991; Sanz 1997: 76-80; Ramallo 
1990: 154). En el caso lorquino, si bien dicha ocupación se observa ya desde época ibérica, será en este periodo cuando por primera vez se documente el desarrollo de un nuevo trazado urbanístico en todo este sector a los pies del cerro (Martínez 2008).

También en esta zona, en distintas áreas del actual casco urbano, se documentan ya de forma amplia abundantes materiales itálicos como en la Plaza de Juan Moreno, la calle Zapatería, el Carril de Caldereros y la calle Floridablanca (García Lorca 2003; Martínez Alcalde 1998; Martínez y Ponce 1999a; Ponce 1999; Pujante 2003a; Ramírez 2004; Sánchez 2002; Sánchez y Medina 2004). En dichos sectores aparecen numerosas importaciones itálicas como ánforas grecoitálicas, Dressel 1 A, 1 B, Dressel 2-4, cazuelas del tipo rojo pompeyano, cerámica de cocina itálica (Vegas 14), cerámica campaniense A (Lamboglia 23, 27, 28, 31, 34, 36 y 68), B y Boide (Lamboglia 1, 2, 3 y 5), que en estos momentos aparecerán aun asociadas a materiales típicamente ibéricos (Martínez Alcalde 2006; Ponce 1998a; Ramallo 1990) (Fig. 7). Junto a ellas, y datados ya en la primera mitad del II a.C., contamos también con algunos hallazgos numismáticos, como el as documentado en la calle Zapatería y el denario republicano con una representación de los Dióscuros a caballo de la calle Eugenio Úbeda (Martínez y Ponce 1999b). Todos ellos presentan un centro marcado ya desde el siglo II a.C. por las influencias romanas.

A pesar de la continuidad del poblamiento en el originario núcleo ibérico en altura y del carácter del Cerro del Castillo como núcleo clave de control del valle y de intercambio, la expansión cada vez mayor de la población por las zonas bajas podría interpretarse en este periodo como consecuencia de una cierta pérdida de vitalidad del mismo. En este sentido, y observando la expansión del poblamiento que se produce en todo el valle y en el entorno de este centro en época imperial, cabe pensar en estas dos centurias previas al cambio de Era como un periodo en el cual, si bien este centro conservará aun un papel destacado en el territorio, irá progresivamente languideciendo a favor de un nuevo modelo de ocupación del mismo que veremos consolidarse con Augusto (Fig. 8). Aun así, el interés de Roma durante los siglos II-I a.C. por mantener el statu quo permitirá aún a este yacimiento, y posiblemente a la élite indígena residente en él, mantener en cierta medida su control sobre estos territorios.

Se mantendrá así durante estos primeros momentos la estructura social definida para el periodo anterior, tal y como sucede en otros ámbitos ibéricos del sur y sureste peninsular (Chapa y Mayoral 1998: 74; Grau 2003; Keay 1996). Esa élite ibérica que ya en el V a.C. vemos presente en el Cerro del Castillo debió de continuar a la cabeza de la sociedad, vién- dose probablemente beneficiada por su proximidad a Carthago Nova y el interés romano por mantener esa organización territorial previa.

De este modo, el cerro pudo conservar su importancia como núcleo articulador de este sector a lo largo de este periodo, si bien irá progresivamente perdiendo la importancia que tuvo en época ibérica. En este sentido aun está por confirmar la hipótesis del posible interés augusteo por convertir este centro en un núcleo romano destacado junto a la nueva calzada, planteada en base a los hallazgos de elementos arquitectónicos monumentales localizados en la cima del cerro (Martínez 2008) (Fig. 11). Aun así, lo cierto es que durante las centurias siguientes no conservará el papel articulador y de control que lo caracterizó a lo largo de los siglos V-III a.C. En este sentido, y como se ha planteado para la comarca de Los Vélez, la proximidad a Carthago Nova y la vinculación económica a ella de estos territorios explicará en gran parte la ausencia de núcleos de población importantes en toda esta área peninsular (Adroher y López 2004: 137-40; Martínez y Muñoz 1999: 146).

A pesar de ello, durante los siglos II-I a.C. cabe aun valorar el papel del Cerro del Castillo desde el punto de vista económico, que continuará funcionando como núcleo redistribuidor de mercancías, tanto locales como llegadas de otras áreas peninsulares y del Mediterráneo. Al mismo tiempo, y como en el periodo precedente, seguirá siendo un punto de almacenamiento de productos, favorecido por su posición privilegiada en la red de comunicaciones, ahora también con Carthago Nova. En este sentido, cabe señalar el gran número de ánforas, especialmente del tipo Mañá D-1 A, recuperadas en los trabajos de desfonde realizados en la Alameda de Menchirón, así como en otros sectores del casco urbano, tales como la calle Floridablan-

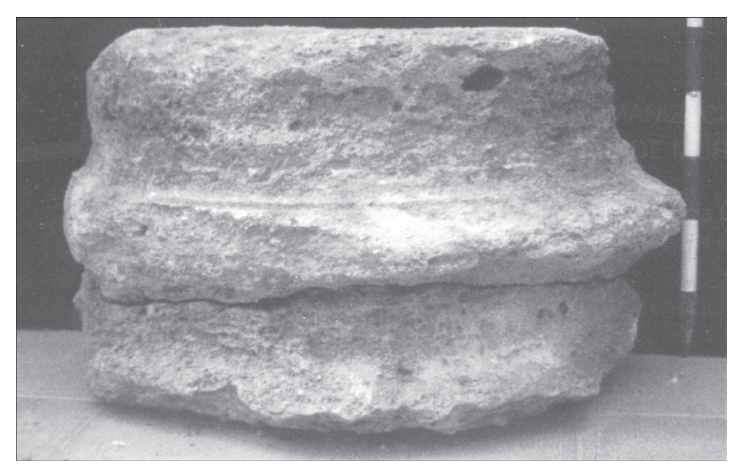

Figura 11.- Basa ática hallada en el Castillo de Lorca (finales del siglo I a.C.) (Martínez Rodríguez 2008: 537, figura 3). 


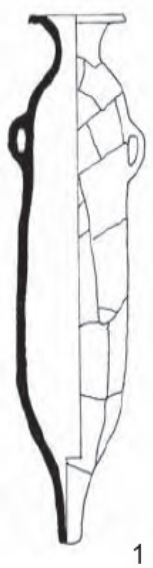

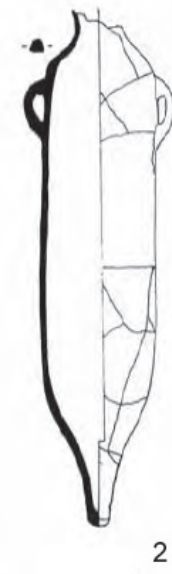

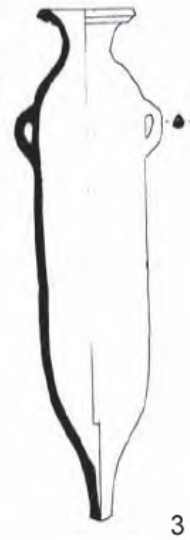

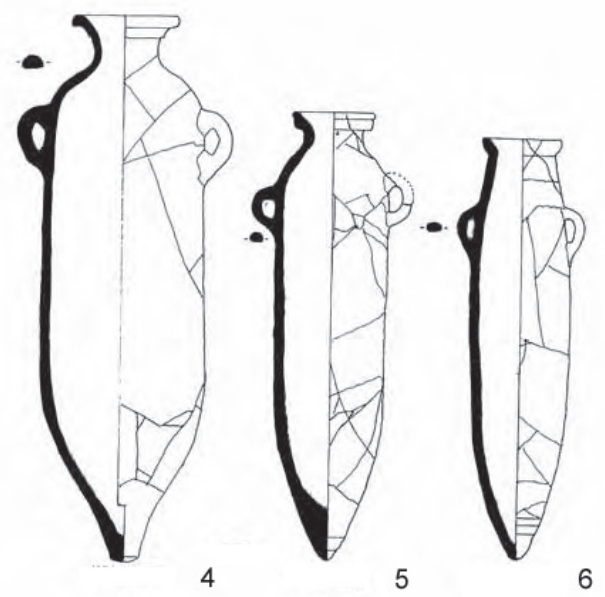

6

Figura 12.- .Depósito de ánforas de La Alberca. 1-3. Mañá C2a; 4. Mañá C ALB/V/60/60027; 5. Mañá C1b ALB/V/52/52011; 6. Ribera G ALB/V/60/60026 (Martínez Alcalde 2006: 238, láminas 9 y 10).

ca, la Plaza de Juan Moreno y La Alberca, donde se halló una habitación de tendencia circular con un depósito con abundantes ánforas completas amortizadas en el 175 a.C. (Martínez 2008) (Figs. 12 y 13). Estos hallazgos han aportado según sus excavadores un número de recipientes tal que permitiría almacenar una cantidad de productos muy superior a la necesaria para el abastecimiento de este centro (Martínez Alcalde 1998: 30-32; Martínez y Ponce 1999a: 229). Todo ello presenta aún en este periodo un núcleo con una destacada participación en los intercambios e inserto en los ejes de comunicación que discurren por todo este sector y que enlazan también con Carthago Nova. En esta línea pueden interpretarse algunas de las importaciones documentadas en este centro, como las cerámicas helenísticas de relieve halladas en la calle Corredera, en el sector de necrópolis, y cuya cronología puede llevarse hasta el último cuarto del II a.C. (Martínez y Ponce 1999a: 229-30).

Al margen de esas importaciones y de los materiales itálicos resulta difícil pensar aún para este periodo en una amplia instalación de itálicos en todo este sector del valle, especialmente si atendemos al carácter indígena que ofrecen los materiales recuperados en el cerro y en el sector de necrópolis (Martínez 2008; Martínez y Ponce 1999a). La población ibérica que ocupa estas tierras a los pies del asentamiento mantendrá sus ritos, cultos y creencias. Así lo refleja la aparición de armamento en tumbas del siglo II a.C. y la pervivencia de enterramientos de incineración en recipientes indíge- nas hasta bien entrado el siglo I d.C. (García Lorca 2003; Pujante 2005: 347; Ramírez 2004).

Tras todo lo indicado está claro que la llegada romana a estos territorios y la toma de Carthago Nova no supuso en ningún momento una ruptura brusca para estos territorios, especialmente si atendemos a los datos aportados por el Cerro del Castillo (Martínez y Ponce 2006). Esta imagen de continuidad que ofrece dicho asentamiento y que tradicionalmente se suele extrapolar al resto del territorio vinculado a él debe matizarse, especialmente si atendemos a dos aspectos. En primer lugar, y como ya indicara M. Pérez (2007: 77), Roma no parece haber llegado nunca a instalarse en el cerro, donde al margen de los restos monumentales indicados no se han localizado restos correspondientes a sectores artesanales o de habitación. Los hallazgos de época romana se localizan a los pies del mismo, no lejos del curso del Guadalentín, quedando el sector en altura únicamente vinculado a época ibérica. En segundo lugar, esa aparente continuidad del oppidum no puede extrapolarse al resto del valle del Guadalentín y del área lorquina. Si bien es cierto que los yacimientos ibéricos documentados durante el periodo anterior continúan en estos momentos, como es el caso del Coto de Los Tiemblos, Los Cantos o La Fuentecica del Tío Garrulo, vemos también surgir ahora nuevos centros que comienzan a transformar el paisaje del valle y que se mantendrán, a diferencia de los surgidos durante las centurias previas, a lo largo del periodo altoimperial. Entre ellos podemos señalar el localizado en Los 


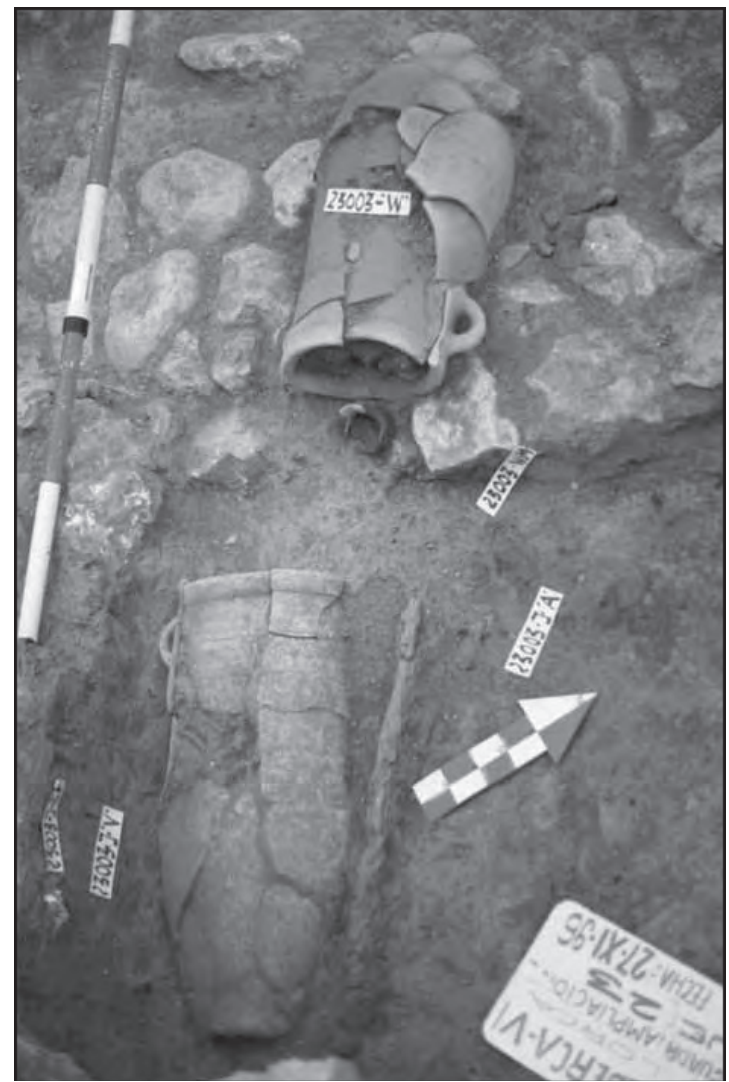

Figura 13.- Ánforas de Campos Numantinos, pequeñas pateritas y un fragmento de soliferrum hallados en las excavaciones del sector de La Alberca (Martínez Alcalde 2006: 231, lámina 6).

Alagüeces, donde se han hallado diversas monedas de época republicana, el ya citado establecimiento de la Torre de Sancho Manuel y, con más dudas, el emplazado en Chíchar (Fontela 1992; Martínez Rodríguez 1996) (Fig. 8). Se trata, en todo caso, de núcleos rurales, posiblemente granjas agropecuarias que comenzarán a desarrollarse en estos momentos y algunas de las cuales alcanzarán una mayor importancia durante el periodo imperial, convirtiéndose en auténticas villae. En la mayor parte de los casos parecen responder a colonizaciones de nuevas tierras, instalándose en sectores no ocupados hasta entonces y en los que no se tiene constancia de la presencia de asentamientos ibéricos en altura durante las centurias previas.

Por lo que respecta a los rasgos concretos que definen estos nuevos centros son las excavaciones realizadas en el localizado en la Torre de Sancho Manuel las que nos ofrecen más información. En éste las estructuras y materiales recuperados, datados desde inicios del II a.C., muestran un asentamiento ibérico con un importante sector artesanal, dedicado a actividades alfareras y formado por dos balsas y un horno de alfarero (Martínez Rodríguez 1995: 151-158).

Así, y si bien la continuidad en la ocupación de los núcleos ibéricos parece clara, al menos durante los primeros momentos del II a.C., el surgimiento de esos nuevos establecimientos que no responden ya al patrón de ocupación ibérico constituye el primer reflejo de los cambios que supondrá la presencia romana en el Sureste y, en definitiva, el primer paso hacia el nuevo paisaje imperial que se desarrollará a partir de Augusto.

\subsection{El Cerro del Castillo en el nuevo paisaje romano}

Desde los momentos finales del I a.C. los nuevos intereses romanos, vinculados a la explotación territorial, provocarán la definitiva desarticulación del modelo organizativo ibérico, dando lugar a una nueva articulación del poblamiento en todo el valle del Guadalentín y mostrando un panorama similar al que define el entorno del vecino Tolmo de Minateda (Albacete) (Sanz 1997: 26-27). La definitiva instalación de la población del cerro en la zona baja y la dispersión de gran parte de la misma en los numerosos centros en llano que surgen en la comarca no será sino la consolidación de esa transformación que veíamos iniciarse ya en los siglos II-I a.C. Como resultado, todo este sector del Sureste, y el propio Cerro del Castillo, pasarán a formar parte del hinterland económico de Carthago Nova.

Desde el punto de vista económico, es cierto que se mantendrán muchas de las actividades desarrolladas desde las centurias anteriores, como las artesanales y especialmente aquellas alfareras, de las que se tiene constancia en las inmediaciones del cerro hasta época tardía (siglos IV-V) (Gallardo et al. 2007; Pérez 2004: 33-34). También las actividades de tipo metalúrgico parecen alcanzar en época imperial un carácter destacado, sin olvidar la importancia que continuarán teniendo los intercambios, especialmente tras la puesta en marcha de la vía Augusta. En este sentido, cabe señalar el hallazgo, en la confluencia de la calle Carril de Caldereros y el número 79 de la Avenida Juan Carlos I, de un edificio de 25 metros de largo, dividido en 5 estancias de idénticas dimensiones e incomunicadas entre sí, destinadas a servicios y comercio. Dichas estructuras han sido interpretadas como un área de tabernae, datada en el siglo I d.C., y junto a la que también se documentó un alfar (Pérez 2004: 33-34). De este modo, los propios hallazgos, así como los materiales recuperados, presentan de nuevo esta zona a los pies del cerro como un área destinada 
claramente a actividades artesanales y comerciales, que marcarán la economía de este núcleo lorquino en época altoimperial (Pérez 2007).

En conexión con esos intercambios también las producciones itálicas, fundamentalmente la terra sigillata, ofrecen interesantes datos en esta línea, apareciendo ya distribuidas por toda la comarca, incluidos aquellos sectores que veremos ocupados a partir de ahora. Entre aquellas producciones localizadas a los pies del Cerro del Castillo, cabría destacar la presencia de terra sigillata itálica (Drag. 17, 27 y 33, Halt. 10 y 15, y Ritt. 5), hispánica (Drag. $15 / 17,24 / 25$ y 21), sudgálica (Drag. 18 y 27), una de ellas con el sello OF:ATIIS, datado en época de Nerón - Domiciano, y africana A (Hayes 5, 3b, $6 \mathrm{~b}, 8,9,14$ y 23). Asimismo se han documentado también ánforas del tipo Dressel 14 y Haltern 70, que ofrecen cronologías encuadradas entre finales del siglo I a.C. y mediados del I d.C. (Bellón 2003: 109-10; Martínez y Ponce 2004; Pérez 2004: 33-34; Sánchez 2004).

De este modo, los establecimientos rurales que surgen a partir de estos momentos, y cuyo florecimiento está claramente vinculado al trazado de la vía Augusta, ofrecen ya un registro material definido por producciones romanas. Todos ellos están además en conexión con una explotación mucho más intensa del territorio a la que responde una ocupación más densa del mismo. A diferencia de la pervivencia de las cerámicas indígenas en toda el área del interior regional, el valle del Guadalentín y los territorios vinculados a él muestran ya un carácter y un paisaje claramente romano. En este sentido basta indicar el patrón de asentamiento y la distribución de los numerosos establecimientos que surgen en toda la comarca, como los instalados en El Villar, Altobordo, Asprodes, Baños de Fuensanta, Cortijo del Centeno, Torralba, El Baldío, El Rincón, La Ermita de los Carrascos o El Lomo (Fig. 14).

La aparición de muchos de estos pequeños centros agropecuarios así como de villae con ricos restos de mosaicos, esculturas y pinturas, en las proximidades del Cerro del Castillo parece indicar la pérdida definitiva del control directo de dicho núcleo sobre las tierras de su entorno. Éstas serán ahora explotadas por esos nuevos asentamientos y englobadas, como el propio cerro, en el hinterland de Carthago Nova, que se constituirá como nuevo foco económico del Sureste. Será esta población la que marcará la dinámica de estos territorios a partir de entonces, y los avatares históricos que afectan a la misma se dejarán sentir también en todo el valle del Guadalentín (Pérez 2007: 77).

La pervivencia de un núcleo como el Cerro del Castillo no encaja de este modo en el nuevo modelo de explotación económica y de ocupación del terri-

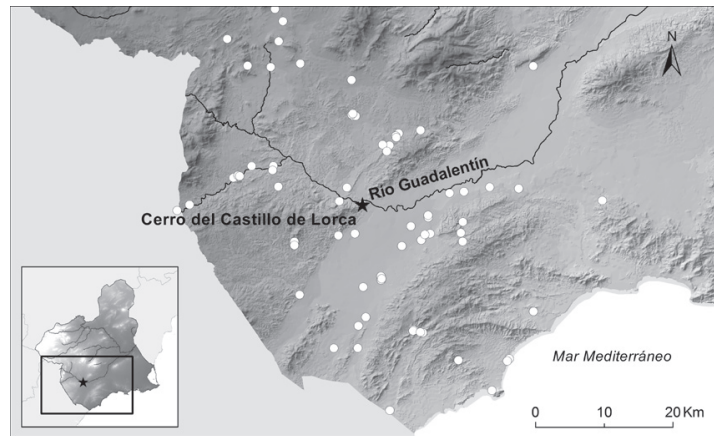

Distribución del poblamiento en el valle medio-alto del Guadalentin durante el periodo altoimperial

$\begin{array}{ll}\star & \text { Cerro del Castillo de Lorca } \\ \text { Yacimientos altoimperiales } & 2020 \text { m.s.n.m. } \\ 0 \mathrm{~m}\end{array}$

Figura 14.- Distribución del poblamiento altoimperial en el entorno del Cerro del Castillo y el valle del Guadalentín.

torio que se configura en el siglo I d.C. y que define estos nuevos centros altoimperiales. Aun así, la posición privilegiada de este establecimiento en el valle del Guadalentín y en las comunicaciones del Sureste favorecerá la continuidad del poblamiento en este sector, siendo aquí donde se localiza en época tardía la mansio de Eliocroca, referida en el Itinerario de Antonino.

\section{Conclusiones}

Como apuntábamos al inicio, los trabajos desarrollados en el Cerro del Castillo y los materiales recuperados han dado a conocer el interés de este centro ibérico. Sin embargo, un análisis diacrónico del mismo, encuadrado en la dinámica del poblamiento del valle del Guadalentín, nos confirma no sólo su importancia en el mundo ibérico del Sureste peninsular sino también el destacado papel que este centro desempeñó en estos territorios entre los siglos V-I a.C.

Desde el punto de vista de la organización del poblamiento la entidad que presenta frente al resto de los núcleos ibéricos documentados en toda la comarca, su amplio dominio visual, sus conexiones con otros posibles puntos de control como el Coto de los Tiemblos y la ausencia de centros en aquellas tierras más próximas a él, que serían explotadas por sus habitantes, lo sitúan claramente a la cabeza de este territorio.

Del mismo modo, los distintos aspectos analizados confirman también su importancia a nivel económico como centro de intercambio y redistribución de productos. En esta línea apuntan, como indicábamos, los materiales recuperados en el asen- 
tamiento y en su necrópolis, así como los múltiples hallazgos relacionados con el desarrollo de actividades artesanales y de intercambio y, en definitiva, su posición clave en una ruta natural y de contacto entre el valle del Segura, el levante peninsular y las tierras andaluzas.

Desde el punto de vista sociopolítico, los datos aportados por el sector de necrópolis muestran la presencia en este yacimiento de un grupo social destacado que manifiesta su diferenciación con respecto al resto de la comunidad a través de elementos comunes a otros oppida ibéricos del Sureste (enterramientos principescos, importaciones áticas). Será precisamente esa élite indígena la que controlará estos territorios y la que articulará la explotación de los mismos, beneficiándose además de los intercambios en los que pudo participar este centro, como demuestran los materiales de importación que caracterizan sus ajuares.

Finalmente, en conexión con el papel de este núcleo como centro de intercambio ya en el siglo $\mathrm{V}$ a.C., cabe mencionar nuevamente el hallazgo de esa posible área de culto en el casco urbano lorquino. El altar documentado ha sido puesto en conexión con la posible actividad comercial de este centro, situándose además en un sector próximo a la entrada del poblado ibérico del siglo $\mathrm{V}$ a.C. (Cárceles et al. 2011: 73-74). Dicho hallazgo, cuyos paralelos no los encontramos precisamente en ambientes ibéricos, refleja también la peculiaridad del oppidum y pone de manifiesto la necesidad de un análisis detenido de las relaciones de esta área regional con el mundo púnico del Sureste, claves para comprender no sólo el desarrollo de este asentamiento sino, a nivel más amplio, el del poblamiento ibérico de todo este sector.

Aun así el panorama y la dinámica que definen a este centro y al valle del Guadalentín a lo largo de las centurias analizadas ofrecen también muchos puntos en común con otros sectores y oppida ibéricos del Sureste. Al igual que en ellos, también en el Guadalentín serán los nuevos intereses romanos los que transformen ese paisaje ibérico. Los grandes núcleos de estos territorios, como el Cerro del Castillo, irán así languideciendo progresivamente para dar paso a un nuevo paisaje claramente marcado ya por la impronta romana.

\section{REFERENCIAS BIBLIOGRÁFICAS}

Adroher, A.M.; López, A. (dirs.) (2004): El territorio de las altiplanicies granadinas entre la Prehistoria y la Edad Media: arqueología en Puebla de Don Fabrique (1995-2002). Junta de Andalucía, Sevilla.

Alías, L.J. (dir.) (1988a): Proyecto LUCDEME. Mapa de suelos. Lorca - 953. Ministerio de Agricultura, Pesca y Alimentación, Madrid.

Alías, L.J. (dir.) (1988b): Proyecto LUCDEME. Mapa de suelos. Puerto Lumbreras - 975. Ministerio de Agricultura, pesca y alimentación, Madrid.

Almagro-Gorbea, M. (1982): Paisaje y sociedad en las necrópolis ibéricas. XVI Congreso Nacional de Arqueología, Cartagena: 725-736.

BELDA, C. (1975): El proceso de romanización de la provincia de Murcia. CSIC, Murcia.

Bellón, J. (2003): Excavación arqueológica de urgencia en C/ Lope Gisbert, 37. Lorca 2002. XIV Jornadas de Patrimonio histórico y Arqueología de la Región de Murcia. Dirección General de Cultura, Murcia: 109-110.

Blánquez, J. (1994): El mundo funerario en la fachada oriental de la Península Ibérica y Andalucía. Los componentes indígena y foráneo. Actas del Encuentro internacional celebrado en Córdoba (3-5 marzo de 1993). Arqueología de la Magna Grecia, Sicilia y Península Ibérica. Córdoba: 315-362.

BRotóns, F.; LóPEZ-MondéJAR, L. (2009): Poblamiento rural romano en el Noroeste. Poblamiento rural romano en el Sureste de Hispania 15 años después (J.M. Noguera, ed.), Universidad de Murcia, Murcia: 413-438.

BRotóns, F.; RAmallo, S.F. (1989): La red viaria romana en Murcia. Los caminos de la Región de Murcia (A. González, coord.), Murcia: 101-120.

CÁmalich, M.D.; Martín, D. (1999): El territorio almeriense desde los inicios de la producción hasta fines de la antigüedad. Un modelo: la depresión de Vera y cuenca el río Almanzora. Junta de Andalucía, Sevilla.

CÁrceles, E.; Gallardo, J.; GonzÁlez, J. A.; Ramos, F. (2008): La necrópolis ibérica de Lorca. Una visión de conjunto. Actas del I Congreso Internacional de Arqueología Ibérica Bastetana, vol. II, Universidad Autónoma de Madrid, Madrid.

CÁrceles, E.; Gallardo, J.; Ramos, F. (2011):Excavaciones urbanas en Lorca: solar esquina calle Álamo con Núñez de Arce (santuario ibérico de tipo orientalizante). Verdolay, 13: 71-81. 
Chapa, T.; MAYORAL, V. (1998): Explotación económica y fronteras políticas: diferencias entre el modelo ibérico y el romano en el límite entre la Alta Andalucía y el Sureste. Archivo Español de Arqueología, 71: 63-77.

Chapa, T.; Pereira, J.; Madrigal, A. (1999): El poblamiento de época ibérica en el área del Guadiana Menor: el caso de Castellones de Céal (Hinojares, Jaén). De las sociedades agrícolas a la Hispania romana. Jornadas Históricas del Alto Guadalquivir (V. Salvatierra; C. Rísquez, eds.). Universidad de Jaén, Jaén: 81-93.

Chávez, E.; Cámalich, M. D.; Martín, D.; González, P. (2002): Protohistoria y Antigüedad en el Sureste peninsular. El poblamiento de la Depresión de Vera y Valle del río Almanzora (Almería). B.A.R. International Series, 1026, Oxford.

Delgado, A.; Fernández, A.; Ruiz, A. (2000): Las transformaciones del s. VI a.n.e. en Andalucía: una visión desde las relaciones entre fenicios e indígenas. Actas del IV Congreso Internacional de Estudios Fenicios y Púnicos, IV, Universidad de Cádiz, Cádiz: 1781-1787.

Esteve, M.A.; Llorens Pascual, M.; Martínez, C. (Ed.) (2003): Los recursos naturales de la Región de Murcia. Un análisis interdisciplinar. Universidad de Murcia, Murcia.

Fernández, M.; Olmos, R. (1986): Las ruedas de Toya y el origen del carro en la Península Ibérica. Museo Arqueológico Nacional, Madrid.

Fontela, S. (1992): La circulación monetaria romana en el valle del Guadalentín. Asociación de Amigos del Museo de Lorca - CAM, Murcia.

Fuentes, N.; García, M. S.; González, P.; Fernández, S.; Carrión, J. S.; López, M.; Medina, J. (2005): Degradación ecológica y cambio cultural durante los últimos cuatro mil años en el sureste ibérico semiárido. Anales de Biología, 27: 69-84.

Gallardo, J.; González, J. A. (2006): Un enterramiento en cista de mampostería hallado en el Cerro del Castillo de Lorca. AlbercA, 4: 51-59.

Gallardo, J.; GonzÁlez, J. A.; Oteo, M. (2007): La actividad alfarera en Lorca: Pervivencia artesanal desde época ibérica hasta el siglo XIX. AlbercA, 5: 135-152.

García CAno, J. M. (1989-1990): Una kylix de la 'clase delicada' procedente de Lorca (Murcia). Anales de Prehistoria y Arqueología, Universidad de Murcia, 5-6: 95-100.

García CANo, J.M. (2004): Contribución al estudio del poblamiento ibérico en el valle del Guadalentín: la cerámica ática de Lorca I. AlbercA, 2: 53-80.

García CANo, J.M. (2008): Los bastetanos más orientales del mar al interior. Las tribus ibéricas en la región de Murcia. Ier Congreso Internacional de Arqueología ibérica Bastetana (A. Adroher, J. Blánquez, eds.). Serie Varia 9, Universidad Autónoma de Madrid, Madrid: 105-124.

García Lorca, S. (2003): Excavación arqueológica de urgencia en c/ Álamo - c/ Rubira, en Lorca (Murcia). ArqueoMurcia, 1 (noviembre 2003), [URL: http://www.arqueomurcia.com/revista/n1/htm/alamo.htm]. [Actualizada el 01/04/2011]. Acceso el 01/04/2011.

García Ruiz, M.; Gallardo, J. (2005): Excavación arqueológica de urgencia en la calle Soler esquina Travesía Soler (Lorca, Murcia). Actas de las XVI Jornadas de Patrimonio Histórico, Dirección General de Cultura, Murcia: 342-343.

García Sandoval, J.; Quiñones, M.; Precioso, M. L. (2006): Extracción, limpieza, consolidación y embalaje de un carro ibérico de hierro, procedente de las excavaciones arqueológicas de calle Corredera, 46 (Lorca). Actas de las XVII Jornadas de Patrimonio Histórico, Dirección General de Cultura, Murcia: 329-332.

GIL, A. (1990): Lorca 1755. Según las Respuestas Generales del Catastro de Ensenada. Tabapress, Madrid.

GRAU, I. (2003): La reorganización del territorio durante la romanización: un caso de estudio en el área central de la Contestania. De Iberia in Hispaniam. La adaptación de las sociedades ibéricas a los modelos romanos (L. Abad, ed.), Universidad de Alicante, Alicante: 53-73.

Iborra, M.P. (2000): Los recursos ganaderos en época ibérica. Saguntum, Extra 3, Ibers. Agricultors, artesans $i$ comerciants: 81-91.

Keay, S.J. (1996): La romanización en el sur y el levante de España hasta la época de Augusto. La Romanización en Occidente (J.M. Blázquez; J. Alvar, eds.). Actas, Madrid: 147-177.

Lillo, P.A. (1990): Economía en la comarca del Guadalentín en el Ibérico Pleno. Lorca. Pasado y presente. Aportaciones a la historia de la Región de Murcia (F. Chacón; A. J. Mula; F. Calvo, coords.), Excmo. Ayuntamiento de Lorca, Murcia: 139-151.

López, F.; Calvo, F.; Morales, A. (1986): Geografia de la Región de Murcia. Ketres, Barcelona. 
Martínez Alcalde, M. (1998): Excavación de urgencia en el solar Alberca VI (Lorca). Resumen de las IX Jornadas de Arqueología Regional, Dirección General de Cultura, Murcia: 30-32.

Martínez Alcalde, M. (1999): Bloques VII y VIII PERI de La Alberca (Lorca). X Jornadas de Arqueología Regional, Dirección General de Cultura, Murcia: 35-36.

Martínez Alcalde, M. (2006): Excavación arqueológica en la zona de La Alberca (Lorca, Murcia). Un horno alfarero de los siglos VII-VI a.C. y un centro comercial y militar de época tardopúnica y romana. Memorias de Arqueología, 14 (1999), Dirección General de Cultura, Murcia: 213-260.

Martínez López, C.; Muñoz, F. A. (1999): Poblamiento Ibérico y Romano en el sureste peninsular: la Comarca de los Vélez (Almería). Universidad de Granada, Granada.

Martínez Rodríguez, A. (1995): El poblamiento rural romano en el valle del Guadalentín. Poblamiento rural romano en el Sureste de Hispania (J.M. Noguera, coord.), Universidad de Murcia, Murcia: 203-226.

Martínez Rodríguez, A. (1996): Primera campaña de excavaciones en la villa romana de la Torre de Sancho Manuel (Lorca). Memorias de Arqueología, 5 (1990), Dirección General de Cultura, Murcia: 142-158.

Martínez Rodríguez, A. (2008): Aportación al estudio de Lorca durante los siglos III al I a.C. Actas del IV Congreso Hispano-Italiano histórico-arqueológico. Iberia e Italia: Modelos romanos de integración territorial (J. Uroz; J. M. Noguera; Coarelli, F., eds.), TABVLARIVM, Murcia: 529-544.

Martínez, A.; Ponce, J. (1999a): Evolución del poblamiento desde época ibérica hasta los inicios de la Romanización en el casco urbano de Lorca (Murcia). XXIV Congreso Nacional de Arqueología, 4, Murcia: $227-238$.

MartíneZ, A.; Ponce, J. (1999b): Excavaciones arqueológicas de urgencia en la calle Eugenio Úbeda, 12-14 (Lorca, Murcia). Memorias de Arqueología, 8 (1993), Dirección General de Cultura, Murcia: 298-329.

Martínez, A.; Ponce, J. (2002a): Aportaciones a los orígenes de la alfarería en Lorca a partir del horno ibérico hallado en la Calle Alonso Fajardo, n. 1. Memorias de Arqueología, 11 (1996), Dirección General de Cultura, Murcia: 379-390.

Martínez, A.; Ponce, J. (2002b): Segunda intervención arqueológica en la Plaza de Juan Moreno, nº 8, confluencia con calle Los Tintes, Lorca. Memorias de Arqueología, 10 (1995), Dirección General de Cultura, Murcia: 149-160.

Martínez, A.; Ponce, J. (2004): Excavaciones arqueológicas de urgencia en un enclave romano y un asentamiento del Neolítico Final en la Calle Floridablanca, espalda Huerto Ruano (Lorca, Murcia). Memorias de Arqueología, 12 (1997), Dirección General de Cultura, Murcia: 291-306.

Martínez, A.; Ponce, J. (2006): De la prehistoria a la actualidad a través de las excavaciones arqueológicas en el Colegio de la Purísima (Lorca). AlbercA, 4: 61-81.

Morgenroth, U. (2004): Southern Iberia in the Early Iron Age. BAR International Series, 1330, Oxford.

Pérez Asensio, M. (2004): Excavación en el solar de avenida Juan Carlos I n 79 con Carril de Caldereros s/n de Lorca. Resumen de las XV Jornadas de Patrimonio histórico y Arqueología de la Región de Murcia, Dirección General de Cultura, Murcia: 33-36.

Pérez Asensio, M. (2007): Un edificio romano de tabernas en Lorca (siglos I-V d.C.). AlbercA, 5: 67-79.

Pérez Carpena, A.D. (1995): Los Vélez durante el periodo ibérico. Revista Velezana 14: 7-12.

Ponce, J. (1997): Excavaciones en el cementerio islámico y necrópolis ibérica de Calle Rubira n 12 (Lorca, Murcia). Memorias de Arqueología, 6 (1991), Dirección General de Cultura, Murcia: 328-362.

Ponce, J. (1998a): Excavación arqueológica calle Cava 20-22 (Lorca, Murcia). Memorias de Arqueología, 7 (1992), Dirección General de Cultura, Murcia: 277-287.

Ponce, J. (1998b): Excavaciones de urgencia en el enclave romano de Carril de Caldereros, Plaza Real, $n^{\circ} 5$ (Lorca, Murcia). Memorias de Arqueología, 7 (1992), Dirección General de Cultura, Murcia: 268-276.

Ponce, J. (1999): Excavaciones arqueológicas de urgencia en Plaza de España, no 2 (Lorca, Murcia). Memorias de Arqueología, 9 (1994), Dirección General de Cultura, Murcia: 346-350.

PovedA, A.M. (1991): Transformación y romanización del hábitat ibérico contestano de las cuencas alta y media del Vinalopó (provincia de Alicante). Del final de la República al Alto Imperio. ALEBUS, 1: 65-78.

Prados, L.; Molina, E.; Álvarez, C. (1991): Las transformaciones del paisaje agrario en época histórica: estudio de las fuentes documentales. El cambio cultural del IV al II milenios a.C. en la comarca Noroeste de Murcia, vol. 1 (P. López, ed.). CSIC, Madrid: 275-313.

Presedo, F.J. (1982): La necrópolis de Baza. Ministerio de Cultura, Madrid. 
Pujante, A. (2003a): Excavación Arqueológica en el Convento de Madres Mercedarias de Lorca. ArqueoMurcia, 1, noviembre 2003. [URL: http://www.arqueomurcia.com/revista/n1/pdf/mercedarias.pdf]. [Actualizada el 01/04/2011]. Acceso el 01/04/2011.

Pujante, A. (2003b): Excavación arqueológica en el solar de Plaza de España 27 (Lorca - Murcia). XIV Jornadas de Patrimonio histórico y Arqueología de la Región de Murcia, Dirección General de Cultura, Murcia: 103105.

Pujante, A. (2005): Excavación arqueológica en calle Núñez de Arce esquina calle Alburquerque (manzana 28finca 4), Lorca (Murcia). Actas de las XVI Jornadas de Patrimonio Histórico, Dirección General de Cultura, Murcia. 347.

Ramallo, S.F. (1990): Problemas históricos y arqueológicos de la Romanización en Lorca. Lorca. Pasado y presente. Aportaciones a la historia de la Región de Murcia (F. Chacón; A. J. Mula; Calvo, F., coord.), Excmo. Ayuntamiento de Lorca, Murcia: 153-161.

Ramírez, J.A. (2004): Excavaciones en calle Corredera 46 y 47 de Lorca. Resumen de las XV Jornadas de Patrimonio histórico y Arqueología de la Región de Murcia, Dirección General de Cultura, Murcia: 113-118.

Ramos, F.; García, M. (2004): Excavación arqueológica de urgencia en calle Rincón de Moncada, Lorca (Murcia). Resumen de las XV Jornadas de Patrimonio histórico y Arqueología de la Región de Murcia, Dirección General de Cultura, Murcia: 109-110.

Rodríguez ArizA, M. O. (1999): La necrópolis ibérica de Galera. Un patrimonio recuperable. La cultura ibérica a través de la fotografía de principios de siglo. Un homenaje a la memoria, vol. 1 (J. Blánquez y L. Roldán, eds.), Patrimonio Nacional, Madrid: 143-152.

Ros, M.M. (1989): Dinámica urbanistica y cultura material del Hierro Antiguo en el valle del Guadalentín. Colegio Oficial de Arquitectos, Universidad de Murcia, Murcia.

Rosselló, V.M. (1968-1969): División comarcal en la provincia de Murcia. Revista Papeles de Geografía, 1: 9-78.

RuIz, A. (1998): Los príncipes iberos: procesos económicos y sociales. Actas del Congreso Internacional. Los Iberos. Príncipes de occidente (C. Aranegui, ed.), Barcelona: 289-300.

Ruiz, A.; Molinos, M. (1993): Los iberos. Análisis arqueológico de un proceso histórico. Cátedra, Barcelona.

Sánchez de Prado, M. D. (2008): Recipientes de vidrio procedentes de un edificio de tabernas de Lorca, Murcia. AlbercA, 6: 61-84.

SÁnchez Gallego, R. (2004): Supervisión arqueológica de urgencia en calle Santo Domingo y callejón de Los Cambrones de Lorca. Resumen de las XV Jornadas de Patrimonio histórico y Arqueología de la Región de Murcia, Dirección General de Cultura, Murcia: 112-114.

SÁnchez González, M.B. (2002): Primera intervención en el solar de calle Los Tintes, esquina con la Plaza de Juan Moreno (Lorca). Memorias de Arqueología, 10 (1995), Dirección General de Cultura, Murcia: 139-148.

SÁnchez GonzÁlez, M.J.; Medina, A.J. (2004): Excavación arqueológica de urgencia en Calle Eugenio Úbeda 7 (Lorca, Murcia). Memorias de Arqueología, 12 (1997), Dirección General de Cultura, Murcia: 307-330.

SANTos, J.A. (1994): Cambios sociales y culturales en época ibérica: el caso del Sureste. CRAN, Madrid.

SANz, R. (1997): Cultura ibérica y romanización en tierras de Albacete: los siglos de transición. Instituto de Estudios Albacetenses, Albacete. 